\title{
The Determination of Optimal Initial Tension in Rat Coronary Artery Using Wire Myography
}

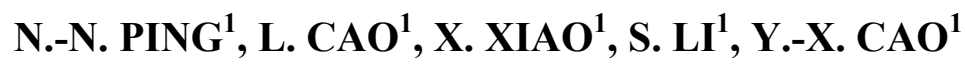 \\ ${ }^{1}$ Department of Pharmacology, Xi'an Jiaotong University College of Medicine, Xi'an, Shaanxi, \\ China
}

Received July 31, 2013

Accepted November 29, 2013

\begin{abstract}
Summary
The aim of the present study was to determine the optimal initial tension, i.e. initial stretch for rat coronary artery when using the multi-wire myograph system. We used the normalization procedure to mimic physiological conditions and to stretch the coronary arterial segments to normalized internal circumference $\left(\mathrm{IC}_{1}\right)$. It is determined the internal circumference when the vessel relaxed under a transmural pressure of $100 \mathrm{~mm} \mathrm{Hg}\left(\mathrm{IC}_{100}\right)$, and the $\mathrm{IC}_{1}$ is calculated by multiplying the $\mathrm{IC}_{100}$ by a factor $k$. The impact of different factor $k$ on the initial stretch and agonistinduced tension of coronary arteries were investigated. The results showed that the maximal agonist-induced tension was achieved at the factor $k$ value of 0.90 and the initial stretch tension was given $1.16 \pm 0.04 \mathrm{mN} / \mathrm{mm}$. The most appropriate factor $k$ value was $0.90-0.95$ and the most appropriate initial tension was $1.16-1.52 \mathrm{mN} / \mathrm{mm}$. The equilibration time of the coronary artery segments should be at least $1.0 \mathrm{~h}$. In the same optimal initial tension, the agonist-induced tension increased as equilibration time lengthened.
\end{abstract}

\author{
Key words \\ Coronary artery - Normalization procedure - Optimal initial \\ tension • Wire myograph $\bullet$ Rat
}

\section{Corresponding author}

Y.-X. Cao, Department of Pharmacology, Xi'an Jiaotong University College of Medicine, 76 Yanta West Road, Xi'an Shaanxi, 710061 P.R. China. E-mal: yxy@xjtu.edu.cn

The tension of blood vessels can reflect vasomotor function. The multi wire myograph system has been widely used to record isometric tension of vessels with internal diameters as little as $80 \mu \mathrm{m}$ in vitro. Rat arteries are the most frequently used blood vessels in the in vitro experiments. A variety of arterial segments including aorta, mesenteric, renal, femoral, cerebral, and coronary arteries (Zhang et al. 2010, Sun et al. 2011, Cao et al. 2013) have been investigated using this device in physiological and pathological state (Uhiara et al. 2012). Many studies have shown that the initial tension, i.e. initial stretch plays an important role in vascular reactivity when using the multi wire myograph system. There is some debate on the appropriate conditions to study arterial segment in different diameters. Generally speaking, if only the optimal initial tension is added, the vessels can achieve the maximum agonist-induced tension. The normalization of rat mesenteric artery and femoral artery has been reported (Slezak et al. 2010). Recently, the research on vasomotor function of coronary artery is increased. However, coronary artery optimal initial tension remains unclear in examining its vasomotor function. In the present study, we focused on the normalization of rat coronary artery in multi wire myograph system. Normalization procedure was used to mimic physiological conditions and to stretch the arterial segment to a normalized internal circumference ( $\left.\mathrm{IC}_{1}\right)$, during which the maximum agonist-induced tension can be obtained. A fully relaxed segment is defined as internal circumference that would have at a specified transmural pressure. For rat mesenteric artery, the transmural pressure is $100 \mathrm{~mm} \mathrm{Hg}$. The internal circumference is abbreviated as $\mathrm{IC}_{100}$. Therefore, normalized internal circumference is then set to $\mathrm{IC}_{1}=k \times \mathrm{IC}_{100}$. In rat mesenteric artery, the factor $k$ value is 
0.9. However, the appropriate factor $k$ for coronary artery is still unknown. Therefore, the present study was designed to investigate the appropriate value of factor $k$ and optimal initial tension in rat coronary artery.

60 Male Sprague-Dawley rats weighting $280 \pm 10 \mathrm{~g}$ were obtained from Experimental Animal Center of Xi'an Jiaotong University College of Medicine, China. This protocol was approved by the Ethical Committee of Xi'an Jiaotong University College of Medicine, China. Rats were sacrificed by $\mathrm{CO}_{2}$. The left anterior descending coronary arteries were gently removed and immediately immersed in cold MOPS solution containing (mM): $\mathrm{NaCl}$ 140, MOPS 2.0, $\mathrm{Na}_{2} \mathrm{HPO}_{4} \cdot 12 \mathrm{H}_{2} \mathrm{O} 1.2$, EDTA $0.02, \mathrm{KCl} 4.7, \mathrm{MgSO}_{4} \cdot 7 \mathrm{H}_{2} \mathrm{O}$ 1.2, $\mathrm{CaCl}_{2} 1.6$ and glucose 5.6 (Ping et al. 2012). The coronary arteries were dissected free of adhering connective tissue under a microscope. The vessels were then cut into approximately 1-2 mm in length, threaded on two thin wires ( $40 \mu \mathrm{m}$ in diameter), and then mounted in myograph baths (Danish Myo Technology A/S, Aarhus, Denmark). One wire was attached to a movable displacement device allowing fine adjustments of vascular tension by varying the distance between the wires. The other was connected to a force displacement transducer attached to an analog-to-digital converter unit (AD Instruments, Hastings, UK). The data were recorded using the software program Chart ${ }^{\mathrm{TM}}$ (AD Instruments, Hastings, UK) (Cao et al. 2012, Sun et al. 2013). The arterial segments were immersed in temperaturecontrolled $\left(37^{\circ} \mathrm{C}\right)$ baths containing $5 \mathrm{ml}$ MOPS solution (pH 7.4). The MOPS solution was continuously gassed with $\mathrm{O}_{2}$.

At the beginning, the two wires going through the arterial segments were adjusted as closely as possible to make the initial stretch of the artery was shown zero. After equilibration for at least $30 \mathrm{~min}$, the ring segments were stretched to their optimal lumen diameter based on the segments length, internal circumference and tension using specific software (LabChart Pro-DMT Normalization module, AD Instruments, Hastings, UK). In order to determine the appropriate value of factor $k$ and initial tension in the coronary artery, normalization procedure was carried out based on the method described by Mulvany and Halpern (1977) using Multi Wire Myograph System - Model 610M. In the setting window of normalization, $\mathrm{IC}_{1} / \mathrm{IC}_{100}$ was set to $0.60,0.70,0.80$, $0.90,0.95$ and 1.00, respectively. The isometric initial tensions were recorded. MOPS solution containing $60 \mathrm{mM} \mathrm{KCl}$ was added to the baths to induce contractive tensions. The greater the contractive tension was, the higher activity of blood vessels has been received during in the same exciting condition. Statistical analysis was carried out using one-way ANOVA followed by post hoc Tukey's test for multiple comparisons. Statistical significance was set at $\mathrm{P}<0.05$. Data are expressed as mean \pm SEM.

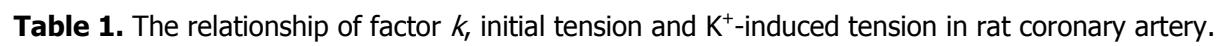

\begin{tabular}{|c|c|c|c|c|}
\hline Factor $k$ & $\mathbf{n}$ & $\begin{array}{l}\text { Initial tension } \\
(\mathbf{m N} / \mathbf{m m})\end{array}$ & $\begin{array}{l}\mathrm{K}^{+} \text {-induced tension } \\
(\mathbf{m N} / \mathbf{m m})\end{array}$ & $\begin{array}{c}\text { Internal circumference } \\
\qquad(\mu \mathrm{m})\end{array}$ \\
\hline 0.60 & 24 & $0.24 \pm 0.02$ & $1.41 \pm 0.13^{* *}$ & $320 \pm 10$ \\
\hline 0.70 & 24 & $0.41 \pm 0.03$ & $1.99 \pm 0.19^{*}$ & $349 \pm 15$ \\
\hline 0.80 & 24 & $0.70 \pm 0.04$ & $2.38 \pm 0.22$ & $411 \pm 21$ \\
\hline 0.90 & 24 & $1.16 \pm 0.04$ & $2.59 \pm 0.17$ & $437 \pm 27$ \\
\hline 0.95 & 24 & $1.52 \pm 0.06$ & $2.53 \pm 0.21$ & $516 \pm 27$ \\
\hline 1.00 & 24 & $2.10 \pm 0.07$ & $2.37 \pm 0.25$ & $530 \pm 33$ \\
\hline
\end{tabular}

Data are presented as mean $\pm \mathrm{SEM}$, and $n$ denotes the number of coronary artery segments. ${ }^{*} P<0.05,{ }^{* *} P<0.01$ compared with factor 0.90

The results in Table 1 showed that the initial tension of the coronary artery segments was increased as the increase of factor $k$. The correlation coefficient between factor $k$ and initial tension was 0.954 , suggesting that the initial tension is proportional to the factor $k$. At the same time, the $\mathrm{K}^{+}$-induced contractive tension was elevated as factor $k$ and initial tension increased. When the factor $k$ and initial tension reached to 0.9 and 1.16 $\mathrm{mN} / \mathrm{mm}$, respectively, the $\mathrm{K}^{+}$-induced contractive tension reached its highest value. Then the contractive tension 
started to decrease as the factor $\mathrm{k}$ or initial tension increased. There was no significant difference of the $\mathrm{K}^{+}$induced contractive tensions among the factor $k 0.8$ to 1.0 or initial tension from 0.7 to $2.1 \mathrm{mN} / \mathrm{mm}$. It means that the scope of the appropriate factor $k$ value and initial tension is wide. The most appropriate factor $k$ value is 0.90-0.95 and the most appropriate initial tension is 1.16$1.52 \mathrm{mN} / \mathrm{mm}$. Most of researchers used approximately $1.0 \mathrm{mN} / \mathrm{mm}$ of initial tension in rat coronary artery segment study. Cheang et al. $(2010,2013)$ stretched each ring to an initial tension of $2 \mathrm{mN}$ when the ring segments were 2-mm long. Li et al. (2012) gave an initial tension of $1.2 \mathrm{mN}$ when the vessels were cut into $1-2 \mathrm{~mm}$ cylindrical segments. Huang and Cao used a $1 \mathrm{mN}$ initial tension and the artery segments were 1-2 mm long (Cao et al. 2012, Huang et al. 2013). These initial tensions were close, but not reached the most appropriate initial tension. However, Sun et al. (2011) stretched each ring to an initial tension of $1.5 \mathrm{mN} / \mathrm{mm}$ which was in the most appropriate range.

Table 2. The effect of equilibrated time on the optimal initial tension in rat coronary artery.

\begin{tabular}{|c|c|c|c|c|c|c|c|}
\hline \multirow[b]{2}{*}{$\begin{array}{l}\text { Equilibrated } \\
\text { time } \\
\text { (h) }\end{array}$} & \multirow[b]{2}{*}{ n } & \multicolumn{3}{|c|}{$k=0.9$} & \multicolumn{3}{|c|}{$k=0.95$} \\
\hline & & $\begin{array}{c}\text { Initial } \\
\text { tension } \\
(\mathrm{mN} / \mathrm{mm})\end{array}$ & $\begin{array}{c}\mathrm{K}^{+} \text {-induced } \\
\text { tension } \\
(\mathrm{mN} / \mathrm{mm})\end{array}$ & $\begin{array}{c}\text { Internal } \\
\text { circumference } \\
(\mu \mathrm{m})\end{array}$ & $\begin{array}{c}\text { Initial } \\
\text { tension } \\
(\mathrm{mN} / \mathrm{mm})\end{array}$ & $\begin{array}{c}\mathrm{K}^{+} \text {-induced } \\
\text { tension } \\
(\mathrm{mN} / \mathrm{mm})\end{array}$ & $\begin{array}{c}\text { Internal } \\
\text { circumference } \\
(\mu \mathrm{m})\end{array}$ \\
\hline 0.5 & 7 & $1.32 \pm 0.11$ & $1.32 \pm 0.23$ & $645 \pm 38$ & $1.83 \pm 0.13$ & $1.85 \pm 0.34$ & $643 \pm 56$ \\
\hline 1.0 & 7 & $1.18 \pm 0.09$ & $1.91 \pm 0.27$ & $534 \pm 61^{*}$ & $1.72 \pm 0.10$ & $2.17 \pm 0.32$ & $515 \pm 31$ \\
\hline 1.5 & 7 & $1.18 \pm 0.11$ & $2.38 \pm 0.37^{*}$ & $465 \pm 23^{* *}$ & $1.67 \pm 0.10$ & $2.44 \pm 0.36$ & $511 \pm 34$ \\
\hline 2.0 & 7 & $1.22 \pm 0.12$ & $2.64 \pm 0.44^{*}$ & $420 \pm 22^{* *}$ & $1.68 \pm 0.14$ & $2.53 \pm 0.32$ & $506 \pm 50^{*}$ \\
\hline 2.5 & 7 & $1.08 \pm 0.10$ & $2.92 \pm 0.42^{* *}$ & $407 \pm 30^{* *}$ & $1.62 \pm 0.11$ & $2.70 \pm 0.33$ & $461 \pm 29^{* *}$ \\
\hline 3.0 & 7 & $1.14 \pm 0.10$ & $3.00 \pm 0.40^{* *}$ & $411 \pm 31^{* *}$ & $1.65 \pm 0.14$ & $2.95 \pm 0.39^{*}$ & $496 \pm 43^{*}$ \\
\hline
\end{tabular}

Data are presented as mean $\pm \mathrm{SEM}$, and $n$ denotes the number of coronary artery segments. ${ }^{*} P<0.05,{ }^{* *} P<0.01$ compared with $0.5 \mathrm{~h}$

The status of the artery could affect the appropriate factor $k$ value and initial tension. We studied the effect of equilibration time on the appropriate factor $k$ value and initial tension. Table 2 showed that the equilibration time had no effect on the initial tension when the factor $k$ values were 0.90 and 0.95 . However, the $\mathrm{K}^{+}$-induced contractive tension in equilibration for $0.5 \mathrm{~h}$ was significantly lower, and the $\mathrm{K}^{+}$-induced contractive tension increased as the equilibration time prolonged.

In conclusion, the accurate factor $k$ and optimal initial tension of rat coronary artery were determined by using wire myography. The maximal $\mathrm{K}^{+}$-induced contractive tension was achieved at the factor $k$ value of 0.90 and the initial tension was given $1.16 \pm 0.04 \mathrm{mN} / \mathrm{mm}$. The most appropriate factor $k$ value was $0.90-0.95$ and optimal initial tension was $1.16-1.52 \mathrm{mN} / \mathrm{mm}$. The equilibration time of the coronary artery segments should be at least $1.0 \mathrm{~h}$.

\section{Conflict of Interest}

There is no conflict of interest.

\section{Acknowledgements}

This work was supported by the National Natural Science Foundation of China (81173059).

\section{References}

CAO L, ZHANG Y, CAO YX, EDVINSSON L, XU CB: Cigarette smoke upregulates rat coronary artery endothelin receptors in vivo. PLoS One 7: e33008, 2012.

CAO L, XU CB, ZHANG Y, CAO YX, EDVINSSON L: Secondhand cigarette smoke exposure causes upregulation of cerebrovascular 5-HT(1) (B) receptors via the Raf/ERK/MAPK pathway in rats. Acta Physiol (Oxf) 207: 183$193,2013$. 
CHEANG WS, WONG WT, SHEN B, LAU CW, TIAN XY, TSANG SY, YAO X, CHEN ZY, HUANG Y: 4-aminopyridine-sensitive $\mathrm{K}^{+}$channels contributes to NaHS-induced membrane hyperpolarization and relaxation in the rat coronary artery. Vascul Pharmacol 53: 94-98, 2010.

CHEANG WS, LAM MY, WONG WT, TIAN XY, LAU CW, ZHU Z, YAO X, HUANG Y: Menthol relaxes rat aortae, mesenteric and coronary arteries by inhibiting calcium influx. Eur J Pharmacol 702: 79-84, 2013.

HUANG LH, ZHANG PA, HE JY, LIU J, CAO YX: DMSO-soluble cigarette smoke particles alter the expression of endothelin B receptor in rat coronary artery. J Vasc Res 50: 238-248, 2013.

LI J, CAO Y-X, YUAN Z-Y, XU C-B: Minimally modified LDL upregulates endothelin type B receptors in rat coronary artery via ERK1/2 MAPK and NF-kappaB pathways. Biochim Biophys Acta 1821: 582-589, 2012.

MULVANY MJ, HALPERN W: Contractile properties of small arterial resistance vessels in spontaneously hypertensive and normotensive rats. Circ Res 41: 19-26, 1977.

PING NN, CAO L, HUANG YR, MI YN, CAO YX: Preparation and pH stability of a physiological salt solution buffered with 3-morpholine propanesulfonic acid. (in Chinese) J Xi'an Jiaotong Univ (Med Sci) 33: 510-514, 2012.

SLEZAK P, WACZULIKOVA I, BALIS P, PUZSEROVA A: Accurate normalization factor for wire myography of rat femoral artery. Physiol Res 59: 1033-1036, 2010.

SUN T, LIU R, CAO YX: Vasorelaxant and antihypertensive effects of formononetin through endothelium-dependent and -independent mechanisms. Acta Pharmacol Sin 32: 1009-1018, 2011.

SUN T, WANG J, HUANG LH, CAO YX: Antihypertensive effect of formononetin through regulating the expressions of eNOS, 5-HT2A/1B receptors and alphal-adrenoceptors in spontaneously rat arteries. Eur J Pharmacol 699: 241-249, 2013.

UHIARA CO, ALEXANDER SP, ROBERTS RE: Simvastatin evokes an unpredicted inhibition of beta-adrenoceptormediated vasodilatation in porcine coronary artery. Eur J Pharmacol 690: 158-163, 2012.

ZHANG HL, ZHAO M, HE X, JIANG HK, YU XJ, MA X, ZANG WJ: Alterations in aortic vasomotor function in rats with chronic heart failure and its mechanism. (in Chinese) Sheng Li Xue Bao 62: 317-324, 2010. 